\title{
Trends in Gallbladder Cancer Incidence and Survival in Korea
}

\section{Youngjun Wi, BS \\ Hyeongtaek Woo, MD \\ Young-Joo Won, PhD2 \\ Jin-Young Jang, MD, $P h D^{3,4}$ \\ Aesun Shin, MD, PhD 1,4}

${ }^{1}$ Department of Preventive Medicine, Seoul National University College of Medicine, Seoul, ${ }^{2}$ Cancer Registration and Statistics Branch, National Cancer Center, Goyang, ${ }^{3}$ Department of Surgery, ${ }^{4}$ Cancer Research Institute, Seoul National University College of Medicine, Seoul, Korea
Correspondence: Aesun Shin, MD, PhD Department of Preventive Medicine, Seoul National University College of Medicine, 103 Daehak-ro, Jongno-gu, Seoul 03080, Korea Tel: 82-2-740-8331

Fax: 82-2-747-4830

E-mail: shinaesun@snu.ac.kr

Received June 9, 2017

Accepted January 23, 2018

Published Online January 24, 2018

\section{Purpose}

The current study was undertaken to examine the trend in gallbladder cancer (GBC) incidence and survival in Korea.

\section{Materials and Methods}

GBC incidence data by histologic type were obtained from the Korea Central Cancer Registry. Age-standardized incidence rates were calculated using the mid-year Korean population of 2000 as a standard population, and a joinpoint regression model was used to calculate the annual percent change (APC) in incidence rates. Incidence by Surveillance, Epidemiology and End Results (SEER) summary stage and by geographical areas and female-to-male incidence rate ratios was also described.

\section{Results}

The number of new GBC cases increased between 1999 and 2013. Nevertheless, the agestandardized incidence rate decreased by $0.5 \%$ per year in men $(p<0.01)$, whereas the incidence rate in women did not change significantly over the same period (APC, -0.2; $p=0.59)$. The most common histologic type was adenocarcinoma in both sexes. Based on the SEER stage, the distant stage was the most frequent stage (41\%), followed by the regional stage (37\%). Ulsan (4.31/100,000 for men and 4.09/100,000 for women in 20092013) and Gyeongsangnam-do (4.15/100,000 for men and 3.54/100,000 for women) showed the highest GBC incidence, whereas the lowest incidence was observed in Seoul and Gyeonggi-do. There were no significant sex differences in the incidence of GBC (femaleto-male incidence rate ratio, 0.96).

\section{Conclusion}

The overall incidence of GBC in Korea did not change significantly over the 15-year period. Incidence for men and women was similar. However, geographical variation was found.

\section{Introduction}

Gallbladder cancer (GBC) is a relatively rare cancer, estimated to constitute $1.3 \%$ of the total cancer incidence worldwide and $1.7 \%$ of all cancer deaths [1]. Nevertheless, the number of epidemiological studies of GBC is insufficient compared to that of other neoplasms because of the low incidence rate and difficulty of tumor registration in GBC, given the anatomical complexity of hepatobiliary tract can-
Key words

Gallbladder neoplasms, Epidemiology, Incidence, Survival, Geographic variation cers [2]. The pathogenesis of GBC, in particular, is poorly known. Unlike other cancers, GBC is usually grouped with other biliary tract cancers in epidemiological research, making it even more difficult to distinguish its epidemiological features [3]. While bile duct cancer is more likely to present with pigment stones, GBC is more likely to present with cholesterol stones, leading to the view that lifestyle factors such as diet and obesity are more closely related to GBC than to bile duct cancer, which is likely to be related to chronic infection or inflammation [4]. 
There is apparent geographical variation in GBC worldwide. The incidence rates are high in Delhi (India), South Karachi (Pakistan), and Quito (Ecuador). High incidence rates are also found in East Asia (Korea and Japan), Eastern Europe (Slovakia, Poland, Czech Republic, and Yugoslavia), and South America (Chile and Colombia) [5,6]. In Asia, studies from India and Japan have reported gallstones, smoking, and alcohol consumption as risk factors for GBC $[7,8]$. In addition, there is a nationwide descriptive epidemiological study in Japan on the stage distribution and survival of GBC [9]. In Korea, GBC and other/unspecified parts of biliary tract cancer showed the 10th highest incidence rate and the sixth highest mortality rate from 2009 to 2013 [10]. As Korea is one of the countries with high GBC incidence rates, the aim of this study was to analyze the current trends in GBC in Korea by histologic type, stage, and geographical distribution.

\section{Materials and Methods}

\section{Trends in GBC incidence}

The Korea Central Cancer Registry (KCCR), a nationwide, hospital-based cancer registry initiated by the Ministry of Health and Welfare in 1980. Since 1999, the KCCR has expanded cancer registration to cover the entire Korean population under the Population-based Regional Cancer Registry program. According to the International Classification of Disease for Oncology, 10th edition, biliary tract cancer is classified into two parts: GBC (C23.9) and other and unspecified parts of biliary tract cancer (C24). Only C23.9 data were used for the current analysis. Age- (5-year intervals) and sexspecific incidence rates and the number of cases of GBC patients between 1999 and 2013 were obtained from the Korea National Cancer Incidence Database. Histological subtypes of GBC were classified as follows: adenocarcinoma, papillary adenocarcinoma, mucinous adenocarcinoma, adenosquamous cell carcinoma, squamous cell carcinoma, oat cell carcinoma, and other specified cancers.

Age-standardized incidence rates (ASRs) were calculated using the world standard population as the standard population. Annual percent changes (APCs) for the incidence rates were calculated based on a linear model using the following formula: $\exp (b) \times 100$, where $b$ is the slope of the regression of the natural logarithm of the ASR in a calendar year. The 95\% confidence intervals were obtained with a standard error from the fit of the regression and the t-distribution function. All analyses were stratified by sex.

\section{Geographical variations in incidence}

The ASRs of GBC by sex were obtained from 17 cities and provinces over three periods (1999-2003, 2004-2008, and 2009-2013). Since ASRs for only 2 years (2012 and 2013) were obtained from Sejong, it was not included in the analysis by provinces. Then, the ASRs were divided into the four index groups defined by quartiles of ASRs per 100,000 population: group 1 (ASR, 0.59-2.66), group 2 (ASR, 2.66-2.92), group 3 (ASR, 2.92-3.55), and group 4 (ASR, 3.55-5.63). The femaleto-male ratio ( $\mathrm{F} / \mathrm{M}$ ratio) was also calculated by region by using the ASRs for the period of 1999-2013.

\section{Stage distribution and 5-year relative survival}

The Surveillance, Epidemiology and End Results (SEER) summary stage was used to group GBC into three categories: localized, regional, and distant. The localized stage is defined as cancer that is limited to the organ in which it began, without evidence of spread. The regional stage is defined as cancer that has spread beyond the primary site to nearby lymph nodes or organs and tissues, and the distant stage is defined as cancer that has spread from the primary site to distant organs or distant lymph nodes. Stage information was available from 2005 and divided into two periods (2005-2008 and 2009-2013) to be compared. The survival duration for GBC patients was determined as the interval between the date of initial diagnosis and the date of death, the date of loss to follow-up, or the closing date for follow-up. Personal identification numbers of patients were linked to the death certificate database of the Korea Statistics Office and followed until December 31, 2015. Patients only found in the death certificate database were excluded from the survival analysis. The 5-year relative survival rates were calculated using the Ederer II method based on an algorithm written in SAS (SAS Institute Inc., Cary, NC) by Dickman [11], with minor modifications.

\section{Ethical statement}

The study has been granted an exemption from ethics approval, since it used public data (exemption approval: Seoul National University Hospital IRB \# E-1601-082-734). 
Table 1. CR and ASR per 100,000 for gallbladder cancer and APC by sex and histological subtype, Korea Central Cancer Registry, 1999-2013

\begin{tabular}{|c|c|c|c|c|c|c|c|}
\hline \multirow{2}{*}{ Histological group } & \multirow{2}{*}{ Rate } & \multicolumn{3}{|c|}{ Year } & \multirow{2}{*}{ APC } & \multirow{2}{*}{$95 \% \mathrm{CI}$} & \multirow{2}{*}{ p-value } \\
\hline & & 1999-2003 & 2004-2008 & $2009-2013$ & & & \\
\hline \multicolumn{8}{|l|}{ Men } \\
\hline \multirow[t]{3}{*}{ Overall } & Cases & 3,202 & 4,039 & 4,856 & & & \\
\hline & $\mathrm{CR}$ & 2.69 & 3.32 & 3.90 & & & \\
\hline & ASR & 3.11 & 3.12 & 2.96 & -0.5 & -1.0 to 0.0 & $<0.01$ \\
\hline \multirow[t]{3}{*}{ Adenocarcinoma } & Cases & 1,156 & 1,761 & 2,732 & & & \\
\hline & CR & 0.97 & 1.45 & 2.19 & & & \\
\hline & ASR & 1.12 & 1.35 & 1.66 & 3.9 & 3.1 to 4.7 & $<0.01$ \\
\hline \multirow[t]{3}{*}{ Papillary adenocarcinoma } & Cases & 60 & 105 & 131 & & & \\
\hline & $\mathrm{CR}$ & 0.05 & 0.09 & 0.11 & & & \\
\hline & ASR & 0.06 & 0.08 & 0.08 & 1.1 & -3.8 to 6.2 & 0.67 \\
\hline \multirow[t]{3}{*}{ Mucinous adenocarcinoma } & Cases & 11 & 27 & 24 & & & \\
\hline & $\mathrm{CR}$ & 0.01 & 0.02 & 0.02 & & & \\
\hline & ASR & 0.01 & 0.02 & 0.01 & - & - & - \\
\hline \multirow[t]{3}{*}{ Adenosquamous cell carcinoma } & Cases & 33 & 34 & 73 & & & \\
\hline & $\mathrm{CR}$ & 0.03 & 0.03 & 0.06 & & & \\
\hline & ASR & 0.03 & 0.03 & 0.05 & 2.1 & -3.9 to 8.4 & 0.47 \\
\hline \multirow[t]{3}{*}{ Squamous cell carcinoma } & Cases & 29 & 27 & 34 & & & \\
\hline & $\mathrm{CR}$ & 0.02 & 0.02 & 0.03 & & & \\
\hline & ASR & 0.03 & 0.02 & 0.02 & -2.1 & -7.2 to 3.3 & 0.44 \\
\hline \multirow[t]{3}{*}{ Oat cell carcinoma } & Cases & 7 & 8 & 30 & & & \\
\hline & $\mathrm{CR}$ & 0.01 & 0.01 & 0.02 & & & \\
\hline & ASR & 0.01 & 0.01 & 0.02 & - & - & - \\
\hline \multirow[t]{3}{*}{ Other specified cancer } & Cases & 77 & 99 & 155 & & & \\
\hline & CR & 0.06 & 0.08 & 0.12 & & & \\
\hline & ASR & 0.08 & 0.08 & 0.09 & 2.5 & -2.1 to 7.2 & 0.27 \\
\hline \multirow[t]{3}{*}{ Unspecified cancer } & Cases & 1,829 & 1,978 & 1,677 & & & \\
\hline & $\mathrm{CR}$ & 1.54 & 1.63 & 1.35 & & & \\
\hline & ASR & 1.78 & 1.54 & 1.03 & -4.9 & -6.3 to -3.5 & $<0.01$ \\
\hline \multicolumn{8}{|l|}{ Women } \\
\hline \multirow[t]{3}{*}{ Overall } & Cases & 4,489 & 5,522 & 6,357 & & & \\
\hline & $\mathrm{CR}$ & 3.82 & 4.58 & 5.12 & & & \\
\hline & ASR & 3.03 & 3.03 & 2.79 & -0.2 & -1.1 to 0.6 & 0.59 \\
\hline \multirow[t]{3}{*}{ Adenocarcinoma } & Cases & 1,639 & 2,222 & 3,313 & & & \\
\hline & $\mathrm{CR}$ & 1.39 & 1.84 & 2.67 & & & \\
\hline & ASR & 1.11 & 1.21 & 1.45 & 2.7 & 2.1 to 3.3 & $<0.01$ \\
\hline \multirow[t]{3}{*}{ Papillary adenocarcinoma } & Cases & 92 & 153 & 151 & & & \\
\hline & $\mathrm{CR}$ & 0.08 & 0.13 & 0.12 & & & \\
\hline & ASR & 0.06 & 0.08 & 0.07 & 2.0 & -3.9 to 8.2 & 0.52 \\
\hline \multirow[t]{3}{*}{ Mucinous adenocarcinoma } & Cases & 20 & 28 & 35 & & & \\
\hline & CR & 0.02 & 0.02 & 0.03 & & & \\
\hline & ASR & 0.01 & 0.02 & 0.02 & 1.8 & -1.6 to 5.4 & 0.28 \\
\hline Adenosquamous cell carcinoma & Cases & 49 & 53 & 81 & & & \\
\hline & $\mathrm{CR}$ & 0.04 & 0.04 & 0.07 & & & \\
\hline & ASR & 0.03 & 0.03 & 0.03 & 1.5 & -2.4 to 5.6 & 0.42 \\
\hline Squamous cell carcinoma & Cases & 29 & 46 & 37 & & & \\
\hline & $\mathrm{CR}$ & 0.02 & 0.04 & 0.03 & & & \\
\hline & ASR & 0.02 & 0.03 & 0.02 & -2.3 & -7.0 to 2.7 & 0.33 \\
\hline
\end{tabular}

(Continued to the next page) 
Table 1. Continued

\begin{tabular}{|c|c|c|c|c|c|c|c|}
\hline \multirow{2}{*}{ Histological group } & \multirow{2}{*}{ Rate } & \multicolumn{3}{|c|}{ Year } & \multirow{2}{*}{ APC } & \multirow{2}{*}{$95 \% \mathrm{CI}$} & \multirow{2}{*}{ p-value } \\
\hline & & $1999-2003$ & 2004-2008 & $2009-2013$ & & & \\
\hline \multirow[t]{3}{*}{ Oat cell carcinoma } & Cases & 12 & 14 & 23 & & & \\
\hline & $\mathrm{CR}$ & 0.01 & 0.01 & 0.02 & & & \\
\hline & ASR & 0.01 & 0.01 & 0.01 & - & - & - \\
\hline \multirow[t]{3}{*}{ Other specified cancer } & Cases & 89 & 103 & 178 & & & \\
\hline & CR & 0.08 & 0.09 & 0.14 & & & \\
\hline & ASR & 0.06 & 0.06 & 0.08 & 2.7 & -1.3 to 6.8 & 0.17 \\
\hline \multirow[t]{3}{*}{ Unspecified cancer } & Cases & 2,559 & 2,903 & 2,539 & & & \\
\hline & $\mathrm{CR}$ & 2.18 & 2.41 & 2.05 & & & \\
\hline & ASR & 1.73 & 1.60 & 1.12 & -3.3 & -4.3 to -2.3 & $<0.01$ \\
\hline
\end{tabular}

$\mathrm{CR}$, crude incidence rate; ASR, age-standardized incidence rate; APC, annual percent change; $\mathrm{CI}$, confidence interval.
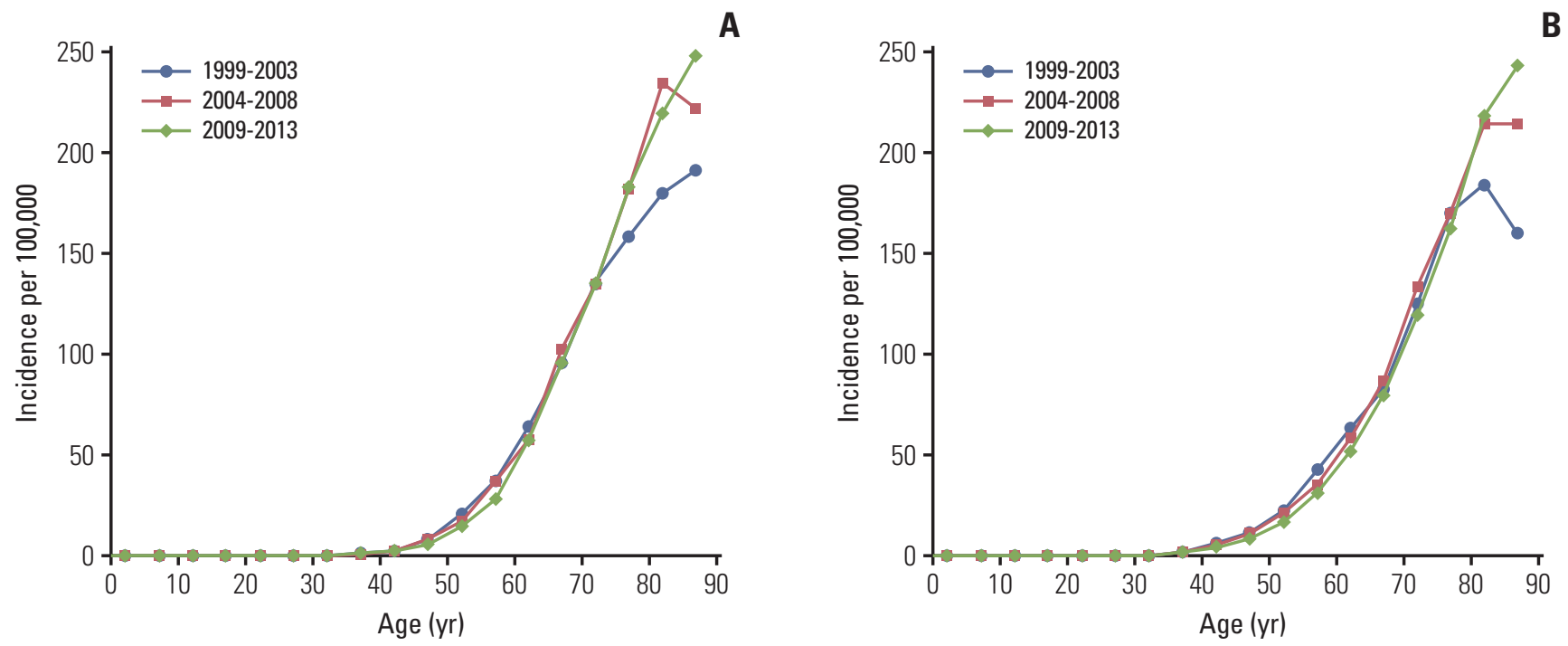

Fig. 1. Age-standardized incidence rates of gallbladder cancer in three periods (1999-2003, 2004-2008, and 2009-2013) for men (A) and women (B).

\section{Results}

\section{GBC incidence and stage distribution}

Table 1 shows the crude incidence rate and ASR of GBC by histologic type from 1999 to 2013 . For men, the ASR of GBC significantly decreased from 3.11/100,000 (1999-2003) to $2.96 / 100,000(2009-2013)$ with an APC of $-0.5 \%(p<0.01)$. The most frequent histologic type of GBC was adenocarcinoma, of which ASR significantly increased from 1.12/ $100,000$ to $1.66 / 100,000$, with an APC of $3.9 \%$ ( $p<0.01)$. In papillary adenocarcinoma, adenosquamous cell carcinoma, squamous cell carcinoma, oat cell carcinoma, and other specified cancers, no significant changes in the ASR were observed.

For women, the ASR decreased from 3.03/100,000 to $2.79 / 100,000$, with an APC of $-0.2 \%$, but this trend was not statistically significant. Similar to that in men, adenocarcinoma in women showed the highest incidence among all histologic subtypes. The ASR of adenocarcinoma in GBC increased substantially from $1.11 / 100,000$ to $1.45 / 100,000$, with an APC of $2.7 \%(\mathrm{p}<0.01)$. In papillary adenocarcinoma, adenosquamous cell carcinoma, squamous cell carcinoma, oat cell carcinoma, and other specified cancers, significant trends in the ASR were not observed. 
A
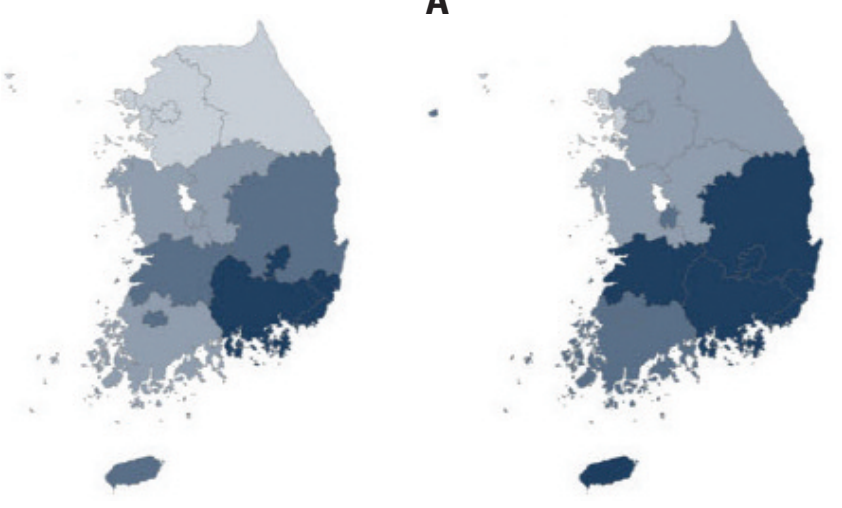

D

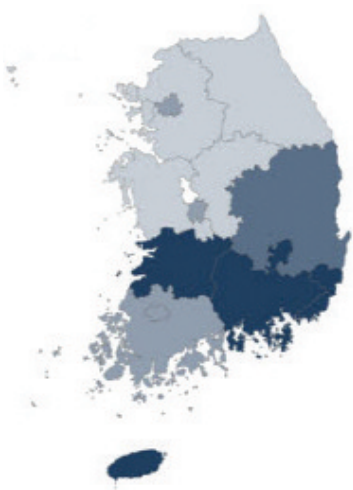

B

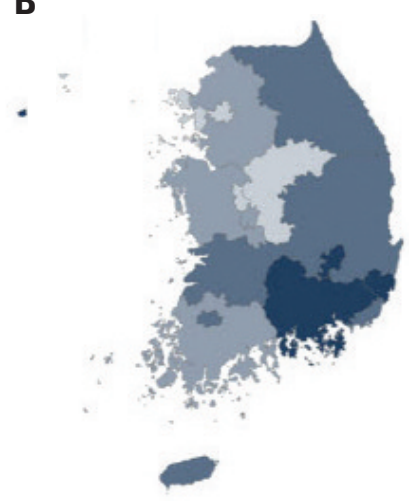

E

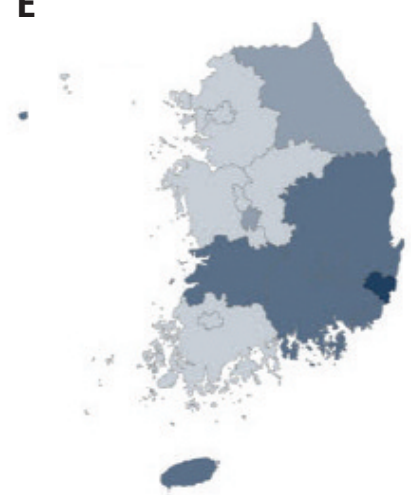

C

$\mathbf{F}$

Gallbladder cancer incidence rates per 100,000 population

0.59-2.66

- $2.66-2.92$

- 2.92-3.55

Fig. 2. Geographic variation in age-standardized incidence rates per 100,000 for gallbladder cancer by province in Korea for men in 1999-2003 (A), 2004-2008 (B), and 2009-2013 (C) and for women in 1999-2003 (D), 2004-2008 (E), and 2009-2013 (F).

In both men and women, GBC incidence increased exponentially by age (Fig. 1). For older age groups ( 80 years and older), the incidence rates increased between 2004 and 2013 compared to 1999-2003.

\section{Geographic difference}

Fig. 2 and S1 Table show the geographic variation in ASRs across 16 cities and provinces in Korea. During 1999 and 2003, the highest incidence in men was observed in Daegu $(5.63 / 100,000)$ and Gyeongsangnam-do $(4.4 / 100,000)$, whereas the highest incidence in women was observed in Jeju $(4.43 / 100,000)$ and Ulsan $(4.34 / 100,000)$. During 2009-2013, the highest incidence was observed in Ulsan $(4.31 / 100,000)$ and Gyeongsangnam-do $(4.15 / 100,000)$ in men and Ulsan $(4.09 / 100,000)$ and Gyeongsangnam-do $(3.54 / 100,000)$ in women.

In most cities and provinces, the $\mathrm{F} / \mathrm{M}$ ratio was below 1 . Only five cities showed an F/M ratio over 1: Seoul, Jeju, Incheon, Busan, and Daejeon. The highest $\mathrm{F} / \mathrm{M}$ ratio was
Table 2. SEER stage distribution of patients with gallbladder cancer in two periods (2005-2008 and 2009-2013)

\begin{tabular}{lll} 
Stage & $\mathbf{2 0 0 5 - 2 0 0 8}$ & $\mathbf{2 0 0 9 - 2 0 1 3}$ \\
Localized & $1,348(21.8)$ & $2,139(21.3)$ \\
Regional & $2,300(37.2)$ & $3,782(37.7)$ \\
Distant & $2,535(41.0)$ & $4,105(41.0)$ \\
Unknown & 1,637 & 1,187 \\
\hline
\end{tabular}

Values are presented as number (\%). SEER, Surveillance, Epidemiology and End Results.

found in Jeju (1.21), followed by Incheon (1.10), Busan (1.07), Daejeon (1.03), and Seoul (1.01).

Table 2 shows the SEER stage distribution of GBC. In two periods (2005-2008 and 2009-2013), most GBC patients, 2,535 $(41.0 \%)$ and $4,105(41.0 \%)$, were diagnosed at the distant stage, followed by 2,300 (37.2\%) and 3,782 (37.7\%) diagnosed 


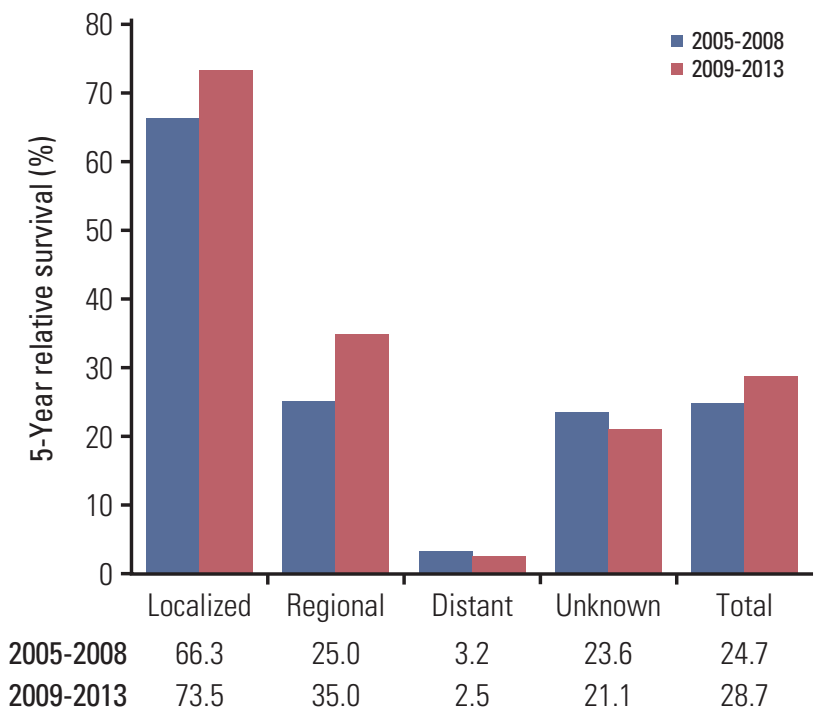

Fig. 3. The 5-year relative survival rate for gallbladder cancer by Surveillance, Epidemiology and End Results summary stage in two periods (2005-2008 and 2009-2013).

at the regional stage, respectively. The percentages of patients diagnosed at the localized stage were the lowest, with 1,348 (21.8\%) and 2,139 (21.3\%) cases, respectively. The percentages for each stage did not change over time.

There was little improvement in the 5-year relative survival in patients with localized or regional stage cancers diagnosed during 2005-2008 and 2009-2013; however, no improvement in survival was observed for patients with distant or unknown stages during the same period (Fig. 3).

\section{Discussion}

Despite the increase in the number of GBC cases for both sexes over fifteen years, the ASR for men decreased, and the ASR for women did not show a significant change. Adenocarcinoma was the most frequent histologic type for both sexes. GBC was diagnosed mostly at distant stages, followed by regional stages. In Korea, the GBC incidence in Daegu, Ulsan, Busan, Gyeongsangbuk-do, Gyeongsangnam-do, and Jeju was higher than the national incidence for both sexes.

The GBC incidence rate was slightly decreased in men, whereas no significant trend was observed in women between 1999 and 2013. In Shanghai, the GBC incidence rate continuously increased for both sexes between 1972 and 1994 [12]. Increasing trends were also observed for both sexes in
England and Wales between 1971 and 2001 [13], while the incidence rate of GBC decreased in the Netherlands between 1989 and 1998 [14]. The incidence pattern was stable in the Dijon area in France [15].

Adenocarcinoma was the most frequent histologic type of GBC in both sexes, for which the ASR increased between 1999 and 2013. However, it is not clear whether this is a true increase, given the high proportion of unspecified cancers and the gradual improvement in the classification. In a nationwide survey of the United States between 1977 and $1988,75.8 \%$ of GBC patients had the adenocarcinoma histological type [16]. According to hospital records, most of the histologic types were adenocarcinoma, accounting for $90 \%$ $100 \%$ of all cases $[3,17]$.

The GBC incidence in Korea was between 2.96 and 3.12 per 100,000 in men and between 2.79 and 3.03 in women. This incidence is relatively higher than the incidence rates in other countries. Known risk factors such as Clonorchis sinensis and factors related to gallstones are widespread in the Korean area [18].

The F/M ratios of GBC in Korea were between 1.21 and 0.83. In most countries, the $\mathrm{F} / \mathrm{M}$ ratios of $\mathrm{GBC}$, including other biliary tract cancers, were higher than 2 [5], and sex has been recognized as a risk factor of GBC [5]. In contrast, Japan and Korea had F/M ratios of only approximately 1.3 [5]. One possible explanation for relatively high incidence of GBC in men than in women is the difference in prevalence of Clonorchis sinensis. It has been reported that prevalence of Clonorchis sinensis was 3.7\% in men and $1.6 \%$ in women in year 1981 [19].

Accordingly, the SEER stage distribution between the two periods did not differ. However, the number of cases at unknown stages decreased, even though the number of overall cases increased. This result can be explained by diagnostic progress. Compared to the American SEER stage distribution, the percentage of cases at the localized stage was lower, and that of the distant stage was greater [20]. In other words, the high incidence of GBC in Korea was not associated with early detection of cancer. The percentage of cases at the TNM stage, according to Korean hospital data, was reported as follows: $\mathrm{T} 1 \mathrm{a}$ and $\mathrm{T} 1 \mathrm{~b}$ stage between $32 \%$ and $56 \%$; T2 stage between $30 \%$ and $55 \%$; and T3 between $3 \%$ and $22 \%$, respectively [21-23].

Daegu, Ulsan, Busan, Gyeongsangbuk-do, Gyeongsangnam-do, and Jeju had higher GBC incidence rates than the national incidence rate for both sexes. There are not enough studies to explain this result. However, this may be related to the egg positive rate of Clonorchis sinensis. This rate is highest in Gyeongsangnam-do, where the GBC incidence rate is also high [24]. However, the second highest egg positive rate was reported in Chungcheongnam-do, where the GBC incidence rate is not as high [24]. Other studies have shown that 
the prevalence of obesity requiring pharmacotherapy was highest in regions with a low incidence rate of GBC, except for in Jeju [25]. Although obesity is a risk factor for GBC, its nationwide distribution is not associated with its distribution in Korea.

One of the known risk factors for GBC is gallstone disease. History of gallstone disease and gallstone size are already known to be associated with GBC risk [26]. Gallstones that are larger in size $(>3 \mathrm{~cm})$, volume, and weight; higher in number; and longer lasting can increase the risk of GBC [27]. Ethnicity is a risk factor for GBC as well [28]. In Chile, a country with high GBC rates, membership in the Mapuche population is the primary risk factor for the increasing GBC incidence [6]. In America, it has also been reported that Korean immigrants have a higher GBC incidence than do whites and blacks [29]. Early age at menarche, high body mass index, and smoking are also risk factors for GBC $[8,30,31]$. Studies show conflicting information regarding alcohol consumption as a risk factor [8].

In the SEER program, it was reported that the 5-year relative survival was $41.9 \%$ at the localized stage, $3.8 \%$ at the regional stage, and $0.7 \%$ at the distal stage from 1973 to 1987 [32]. Our results showed higher survival rates at all stages during the study period.

Limitations of the current study include a relatively high proportion of unspecified histology. The proportion of unspecified cancer in men was $60.8 \%$ in the first period (from 1999 to 2003) and improved to $36.8 \%$ in the most recent period (from 2009 to 2013). In women, the proportion of unspecified cancer was 59.1\% from 1999 to 2003 and decreased to $43.8 \%$ from 2009 to 2013. Another limitation includes relatively high proportions of cases at an unknown stage, although this proportion has decreased as follows: 19.7\% from 2005 to 2008 and 9.8\% from 2009 to 2013. In addition, although the proportion of death certificate only $(\%)$ was in reasonable range during the study period, limited validity in the proportion of microscopic verification (\%) was observed for GBC (S2 Table).

In spite of the limitations, the KCCR provides nationwide data covering the entire Korean population with high completeness.

In summary, the overall incidence pattern of GBC in Korea is stable. The incidence of GBC for fifteen years in Korea did not show significant changes. Incidence for men and women was similar. There was geographical variation in the incidence of GBC.

\section{Electronic Supplementary Material}

Supplementary materials are available at Cancer Research and Treatment website (http://www.e-crt.org).

\section{Conflicts of Interest}

Conflict of interest relevant to this article was not reported.

\section{Acknowledgments}

This work was supported by a grant from Seoul National University Hospital (2016).

\section{References}

1. Ferlay J, Soerjomataram I, Dikshit R, Eser S, Mathers C, Rebelo $\mathrm{M}$, et al. Cancer incidence and mortality worldwide: sources, methods and major patterns in GLOBOCAN 2012. Int J Cancer. 2015;136:E359-86.

2. Hundal R, Shaffer EA. Gallbladder cancer: epidemiology and outcome. Clin Epidemiol. 2014;6:99-109.

3. Butte JM, Matsuo K, Gonen M, D'Angelica MI, Waugh E, Allen PJ, et al. Gallbladder cancer: differences in presentation, surgical treatment, and survival in patients treated at centers in three countries. J Am Coll Surg. 2011;212:50-61.

4. Hsing AW, Gao YT, Han TQ, Rashid A, Sakoda LC, Wang BS, et al. Gallstones and the risk of biliary tract cancer: a population-based study in China. Br J Cancer. 2007;97:1577-82.

5. Randi G, Franceschi S, La Vecchia C. Gallbladder cancer worldwide: geographical distribution and risk factors. Int J Cancer. 2006;118:1591-602.

6. Andia ME, Hsing AW, Andreotti G, Ferreccio C. Geographic variation of gallbladder cancer mortality and risk factors in Chile: a population-based ecologic study. Int J Cancer. 2008; 123:1411-6.

7. Sachidananda S, Krishnan A, Janani K, Alexander PC, Velayutham V, Rajagopal S, et al. Characteristics of gallbladder cancer in South India. Indian J Surg Oncol. 2012;3:228-30.

8. Yagyu K, Kikuchi S, Obata Y, Lin Y, Ishibashi T, Kurosawa M, et al. Cigarette smoking, alcohol drinking and the risk of gallbladder cancer death: a prospective cohort study in Japan. Int J Cancer. 2008;122:924-9.

9. Kayahara M, Nagakawa T. Recent trends of gallbladder cancer in Japan: an analysis of 4,770 patients. Cancer. 2007;110: $572-80$.

10. Oh CM, Won YJ, Jung KW, Kong HJ, Cho H, Lee JK, et al. Cancer statistics in Korea: incidence, mortality, survival, and prevalence in 2013. Cancer Res Treat. 2016;48:436-50.

11. Dickman P [Internet]. PaulDickman.com [cited 2018 Jan 2]. 
Available from: http//www.pauldickman.com.

12. Jin F, Devesa SS, Chow WH, Zheng W, Ji BT, Fraumeni JF Jr, et al. Cancer incidence trends in urban shanghai, 1972-1994: an update. Int J Cancer. 1999;83:435-40.

13. West J, Wood H, Logan RF, Quinn M, Aithal GP. Trends in the incidence of primary liver and biliary tract cancers in England and Wales 1971-2001. Br J Cancer. 2006;94:1751-8.

14. Siesling S, van Dijck JA, Visser O, Coebergh JW; Working Group of The Netherlands Cancer Registry. Trends in incidence of and mortality from cancer in The Netherlands in the period 1989-1998. Eur J Cancer. 2003;39:2521-30.

15. Manfredi S, Benhamiche AM, Isambert N, Prost P, Jouve JL, Faivre J. Trends in incidence and management of gallbladder carcinoma: a population-based study in France. Cancer. 2000; 89:757-62.

16. Henson DE, Albores-Saavedra J, Corle D. Carcinoma of the gallbladder: histologic types, stage of disease, grade, and survival rates. Cancer. 1992;70:1493-7.

17. Roa I, Araya JC, Villaseca M, Roa J, de Aretxabala X, Ibacache G. Gallbladder cancer in a high risk area: morphological features and spread patterns. Hepatogastroenterology. 1999;46: 1540-6.

18. Choi D, Lim JH, Lee KT, Lee JK, Choi SH, Heo JS, et al. Gallstones and Clonorchis sinensis infection: a hospital-based casecontrol study in Korea. J Gastroenterol Hepatol. 2008;23 (8 Pt 2):e399-404.

19. Qian MB, Chen YD, Liang S, Yang GJ, Zhou XN. The global epidemiology of clonorchiasis and its relation with cholangiocarcinoma. Infect Dis Poverty. 2012;1:4.

20. Kiran RP, Pokala N, Dudrick SJ. Incidence pattern and survival for gallbladder cancer over three decades: an analysis of 10301 patients. Ann Surg Oncol. 2007;14:827-32.

21. Choi SB, Han HJ, Kim CY, Kim WB, Song TJ, Suh SO, et al. Incidental gallbladder cancer diagnosed following laparoscopic cholecystectomy. World J Surg. 2009;33:2657-63.
22. Kwon W, Jang JY, Lee SE, Hwang DW, Kim SW. Clinicopathologic features of polypoid lesions of the gallbladder and risk factors of gallbladder cancer. J Korean Med Sci. 2009;24: 481-7.

23. Jang JY, Kim SW, Lee SE, Hwang DW, Kim EJ, Lee JY, et al. Differential diagnostic and staging accuracies of high resolution ultrasonography, endoscopic ultrasonography, and multidetector computed tomography for gallbladder polypoid lesions and gallbladder cancer. Ann Surg. 2009;250:943-9.

24. Kim TS, Cho SH, Huh S, Kong Y, Sohn WM, Hwang SS, et al. A nationwide survey on the prevalence of intestinal parasitic infections in the Republic of Korea, 2004. Korean J Parasitol. 2009;47:37-47.

25. Park YW, Choi KB, Kim SK, Lee DG, Lee JH. Obesity in Korean men: results from the Fourth through Sixth Korean National Health and Nutrition Examination Surveys (2007 2014). World J Mens Health. 2016;34:129-36.

26. Lowenfels AB, Walker AM, Althaus DP, Townsend G, Domellof L. Gallstone growth, size, and risk of gallbladder cancer: an interracial study. Int J Epidemiol. 1989;18:50-4.

27. Shrikhande SV, Barreto SG, Singh S, Udwadia TE, Agarwal AK. Cholelithiasis in gallbladder cancer: coincidence, cofactor, or cause! Eur J Surg Oncol. 2010;36:514-9.

28. Stinton LM, Shaffer EA. Epidemiology of gallbladder disease: cholelithiasis and cancer. Gut Liver. 2012;6:172-87.

29. Lee J, Demissie K, Lu SE, Rhoads GG. Cancer incidence among Korean-American immigrants in the United States and native Koreans in South Korea. Cancer Control. 2007;14:78-85.

30. Jee SH, Yun JE, Park EJ, Cho ER, Park IS, Sull JW, et al. Body mass index and cancer risk in Korean men and women. Int J Cancer. 2008;123:1892-6.

31. Shin A, Song YM, Yoo KY, Sung J. Menstrual factors and cancer risk among Korean women. Int J Epidemiol. 2011;40: 1261-8.

32. Carriaga MT, Henson DE. Liver, gallbladder, extrahepatic bile ducts, and pancreas. Cancer. 1995;75(1 Suppl):171-90. 